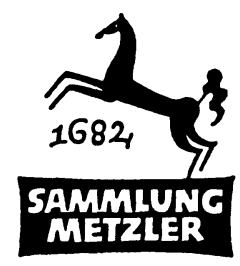

REALIEN ZUR LITERATUR

ABT. E:

POETIK 


\title{
Geschichte der Poetik
}

\author{
Ein Abriß
}

MCMLXXVII

J. B. METZLERSCHE VERLAGSBUCHHANDLUNG

STUTTTGART 
CIP-Kurztitelaufnahme der Deutschen Bibliothek Wiegmann, Hermann

Geschichte der Poetik: e. Abriss. - 1. Aufl. Stuttgart: Metzler, 1977.

(Sammlung Metzler; M 160: Abt. E, Poetik) ISBN 978-3-476-10160-0

ISBN 978-3-476-10160-0

ISBN 978-3-476-03866-1 (eBook)

DOI 10.1007/978-3-476-03866-1

\section{160}

(C) Springer-Verlag GmbH Deutschland 1977

Ursprünglich erschienen bei J. B. Metzlersche Verlagsbuchhandlung und Carl Ernst Poeschel Verlag GmbH in Stuttgart 1977 
Vorbemerkung . . . . . . . . . . VII

Teil I: Geschichte der Poetik bis zum Vorbarock . . . . 1

1. Mimesis und Techne. Die griechische Grundlegung der Poetik . . . . . . . . . . . . . . . . 1

2. Von der Techne zur Ars. Die römische Rhetorisierung der Poetik . . . . . . . . . . . . 13

3. Poetria und die Artes. Die mittelalterliche Adaption der Antike und die Funktion des Christlichen . . . . 20

4. Poeta eruditus. Humanismus und Renaissance . . . . 30

Teil II: Geschichte der deutschen Poetik vom Barock bis zur Moderne . . . . . . . . . . . . . . . . . . . 44

1. Rede- und Ticht-Kunst. Von Opitz bis zur Breslauer Poetik . . . . . . . . . . . . . . . 44

2. Vernunft und Einbildungskraft. Von Gottsched bis zum Sturm und Drang . . . . . . . . . . . 56

3. Philosophie und Dichtung. Klassik/Romantik zwischen Kant und Hegel . . . . . . . . . . . 87

4. Der Reflex der Wirklichkeit. Von der Biedermeierzeit bis zum Realismus . . . . . . . . . . . . 114

5. Imitatio und Creatio. Vom Naturalismus bis zum Expressionismus ................

6. Wissenschaftstheorie und Poetik. Neue Ansätze der Moderne . . . . . . . . . . . . 155

Register . . . . . . . . . . . . . . . 169 


\section{VORBEMERKUNG}

Poetik als Lehre von der Dichtung bzw. von der Dichtkunst bedeutet sowohl dichtungstheoretische Reflexion über die spezifische Eigenart eines Dichtwerks, seinen möglichen Sinn, seinen Zweck, die Begründung seiner Formen und Gattungen, als auch - vorwiegend in normierender Absicht - Technik der poetischen Verfahrensweisen.

Eine Geschichte der Poetik hat die sich historisch entfaltenden unterschiedlichen Vorstellungen von der Dichtung sicher nicht additiv zu erfassen, sondern die nennenswerten poetologischen Beiträge in ihrem historischen Stellenwert zu verdeutlichen, die wichtigsten Entwicklungslinien scharf nachzuzeichnen, wobei die historisch bedeutsamen Beiträge in der Analyse ihrer zentralen Aspekte eingehender behandelt, weniger bedeutsame in einem knappen historischen Abriß nur in einer klärenden Ortsbestimmung benannt werden können.

Bruno Markwardts Lebenswerk, die fünfbändige "Geschichte der deutschen Poetik «, wird aus mehreren Gründen erfahrungsgemäß im Wissenschaftsbetrieb der Germanistik kaum verwandt. Aus der Stoffülle sind für den Leser die entscheidenden historischen Entwicklungen nur schwer zu abstrahieren, zumal Markwardt häufig das historisch Bedeutsame nicht erkennbar von Nebensächlichkeiten trennt. Ein grundsätzlicher Fehler der historischen Analyse ist die Vernachlässigung der außerdeutschen Poetik vor dem Barock und späterhin, weswegen bei ihm oft tradierte Formelhaftigkeit "nationalgeistgeschichtlich" wie Markwardt sich ausdrückt - gedeutet wird. Schließlich ist das Werk (der erste Band erschien 1937) teils nicht mehr auf der Höhe des Forschungsstandes. So ist die verdienstvolle Arbeit Markwardts, der die ungeheure Stoffmenge erstmals geordnet hat, inzwischen $\mathrm{zu}$ einem unübersichtlichen Monument poetologischer Fakten geworden, so daß der Versuch berechtigt erscheint, einen übersichtlichen Abriß vorzulegen, der sich bewußt auf einen Band beschränkt. Es scheint nämlich sinnvoller zu sein, entweder die Originaltexte mit Einführungen und begriffsklärendem Kommentar herauszugeben (die Originaltexte muß man zweifellos trotz oder wegen Markwardt lesen!) oder aber sich von vornherein auf einen knappen Abriß zu beschränken, der eine Hilfe zur Orientierung bietet und die Lektüre der historischen Originaltexte in keinem Fall erspart.

In diesem Band ist es unerläßlich, im angemessenen Rahmen auch die Beiträge zur Ästhetik zu berücksichtigen, wenn sie für 
die historische Poetik wichtig waren. Auch dichtungstheoretische Reflexionen ohne systematische Absicht sind neben den eigentlichen Poetiken erläutert, wenn sie historische Bedeutung hatten. Die Gattungspoetik bedürfte eines eigenen Bandes, sie ist nur dann besprochen worden, wenn sie bemerkenswerte Anstöße für die poetologische Prinzipienlehre vermittelt hat oder im Gesamt der thematisierten Dichtungstheorie von Einfluß war. Es ist auch kein Abriß einer historischen Formenlehre beabsichtigt.

Die historischen Bezüge der Rhetorik zur Poetik sind offenkundig, sie werden selbstverständlich behandelt, soweit sie die eigentliche Poetik einer Epoche betreffen.

Die Literaturangaben beschränken sich auf die wichtigsten bibliographischen Verweise, da für die Sammlung Metzler ein bestimmter Umfang nicht überschritten werden konnte. Wer aber den Titelhinweisen folgt, wird informative weiterführende Hilfen erhalten.

Der Verfasser hat vielen Bibliotheken für die Einsicht in nichtedierte Texte zu danken. Wenn dieser Band - wie mir gesagt wurde - einem dringenden Desiderat germanistischer Lehre nachkommt, wobei er vornehmlich Studenten nützlich sein sollte, so hoffe ich, die daran geknüpften Erwartungen nicht flugs zu enttäuschen. 